\title{
Non - Financial Factors Influencing Entrepreneurial Growth of Agribusiness and Service Based Micro, Small and Medium Enterprises in Mombasa County, Kenya
}

\author{
SanyaJackline Josephine, TheuriFridah (PhD) \\ Jomo Kenyatta University of Agriculture and Technology
}

\begin{abstract}
This study was prompted by paucity in research specifically targeting non-financial factors influencing growth of MSMEs. With most existing studies indicating overemphasis on the contribution of financial factors, the need to shift to the contribution of the non-financial factors on growth of MSMEs; an important sector in developing countries such as Kenya becomes even more urgent. A descriptive survey of managers/owners of registered MSME in Mombasa county sampled using stratified random sampling was undertaken. Out of a sample of 230, 203 useful questionnaires were returned. Data obtained using selfadministered questionnaires to the managers/owners of the MSMEs was analyzed quantitatively using descriptive statistics as well as inferentiallywith the aid of Statistical Package for Social Sciences (SPSS) version 20 computer software. Specifically, descriptive statistics in the form of frequencies, percentages, mean and standard deviation was used to show various relevant distributions while the relationship between the variableswas tested using Chi - square, Contingency Coefficient measure of association and Multiple Linear Regression (MLR). Findings indicated that Proprietors' level of education $(\beta=-2.175 ; P<.001)$, seminar attendance $(\beta=-3.109 ; P<.001)$ and entrepreneurial policies $(\beta=-0.234 ; P<0.001)$ each have a negative significant influence on the growth of the MSMEs. The study also illustrated that enterprise location $(\beta=0.291$; $p<.001)$ and technology integration $(\beta=0.367 ; p<.001)$ significantly promote the growth of the entities. It is therefore recommended that stakeholders including relevant government agencies should put in place measures aimed at enhancing the growth of the MSMEs.Seminars and workshops should be organized and the MSME proprietors/operators be sensitized to attend, minimize cost of moving goods to business location, labour cost on location and transport cost on location. At the same time proprietors should focus more on the efficient use of available technology to maximize on their attendant benefits, funds in form of affordable loans should be made available to the proprietors to enable them invest in new and appropriate technology. Lastly, improve infrastructure, formulate simple and sector friendly tax regime as well as strengthen legal infrastructure.
\end{abstract}

Keywords: Enterprise, Entrepreneur.

\section{INTRODUCTION}

MSMEs offer essential and valuable service to their clientele who are the majority of the population of developing countries such as Kenya. Just like most MSMEs, it has been observed that agribusiness, trade and service based MSMEs face several challenges in spite of their significance in terms of creation of jobs and thus a source of livelihood to a critical mass of the population of many developing countries (Aris, 2007; Saleh \&Ndubisi, 2006; Wambugu\&Ngugi, 2013). This means that the sustenance of such entities are of paramount importance and thus concerted effort needs to be put in place to ensure that the institutions are well operated to not only guarantee their lifespan but also maximize the quality of service that they offer to the citizenry.

Despite their significance, past statistics indicate that three out of five MSME businesses fail within the first few months of operation (Kenya National Bureau of Statistics, 2007) and very few survive beyond the fifth year. This is due to the fact that it is generally recognized that MSMEs face unique problems, which affect their growth and profitability and, hence, diminishes their ability to contribute effectively to sustainable development. The problems according to early studies include lack of access to credit, inadequate managerial and technical skills, low levels of education, poor market information, inhibitive regulatory environments, and lack of access to technology (Harper, 1974; ILO, 1989; House et al., 1991). Recent studies have shown that other factors include poor infrastructure (Bokea, Dondo\&Mutiso, 1999), negative perception towards MSMEs (Amyx, 2005), lack of planning, improper financing and poor management (Longeneckeret al., 2006). 
Empirical data on the extent and influence of various factors on the growth and sustainability of the entities would go a long way in enabling stakeholders and operators of the MSMEs to strategically position themselves thus tap into the readily available market for their products and services. While various studies have underscored the impacts of different factors on growth and sustainability of MSMEs, a cursory analysis of these studies shows that a majority of them have tend to concentrate on the contributions of financial factors (Wambugu\&Ngugi, 2013). Generally, researchers agree that availability of financial services to MSMEs does not necessarily guarantee their success since it has been observed that some of them still face challenges even with adequate financial support. This means that knowledge and adequate stakeholders' awareness on the extent and effect of financial and non - financial factors on the growth and sustainability of the entities is of essence. However, to date and though studies on the effects of financial factors are readily available, there exist minimal empirical data on the unique contributions of non - financial factors on the growth and sustainability of MSMEs within the country (Nyaga, 2013). This study therefore sought to review selected trade, service and agribusiness based MSMEs to assess the impact of non - financial factors on their operations with specific focus of the entities in Mombasa County, Kenya.

\section{NON-FINANCIAL FACTORS AND GROWTH OF MSMES}

\subsection{Proprietors' Demographic Factors}

Researchers have alleged that a majority of those who run MSMEs are ordinary lot whose educational background is lacking. Hence they may not be well equipped to carry out managerial routines for their enterprises (King \& McGrath, 2002). Education and skills are needed to run business entities, micro and small enterprises included. Thus, a majority of the lot carrying out micro and small enterprises in Kenya are not quite well equipped in terms of education and skills. The study suggests that those with more education and training are more likely to be successful in the MSME sector King and McGrath (2002) and for small businesses to do well in, people need to be well informed in terms of skills and management. According to Wanjohi and Mugure, (2008), MSMEs in ICT appear to be doing well with the sprouting of many commercial colleges offering various computer applications. The researchers allege that most of those running the MSMEs in this sector have at least attained college level education. They are categorical that in situations where MSMEs owners or managers lack managerial training and experience, the typical owner or managers develop their own approach to management, through a process of trial and error. As a result, their management style is likely to be more intuitive than analytical, more concerned with day-to-day operations than long-term issues, and more opportunistic than strategic in its concept. Although this attitude is the key strength at the startup stage of the enterprise because it provides the creativity needed, it may present problems when complex decisions have to be made. A consequence of poor managerial ability is that MSME owners are ill prepared to face changes in the business environment and to plan appropriate changes in technology.

Similarly, Macpherson and Holt (2007), maintain that a firm's growth is dependent on the managerial knowledge. However, SMEs face difficulties employing and retaining skilled graduates, because they prefer to work for large enterprises that can offer higher salary, job security and career possibilities. In order to meet the demands of the fast changing work environment which is typically associated with MSMEs, it is essential that smaller firms ensure that they are able to attract, retain and motivate high quality employees with effective transferable skills through the existence of a strategic training plan and a specific budget for training (Jameson, 2004).

\subsection{Enterprise Location}

The location of an enterprise (business) must be accessible to the customer base and should be built to ensure efficient accessibility for future clients (Herzonget al, 2009). When choosing a location the business must take into account the costs of moving or establishing their business in the location. Quoting an online article source (ezinearticles), Nyaga (2013) suggests that when choosing locations, many different factors must be taken into account. According to the researcher, the essential location factors include labour costs, transport, and proximity to suppliers, workforce disruption, language factors, and exchange rates.

Similarly, Herzonget al, (2009) maintains that the change that initiates a location search is the need for new production capacity to meet market demand. The change that that initiates a location search could be changes in perceived market opportunities, or changes in the entrepreneur's own situation. 
After location consideration the decisions makers they can gather information on the tax levels, wagerate levels, and other cost levels at various locations.

\subsection{Technology Integration}

Empirical data shows that access and use of technology has posed a great challenge to small businesses (Calice, Chando\&Sekioua, 2012). Since the mid-1990s there has been a growing concern about the impact of technology on the work of micro and small enterprises. Even with change in technology, many small business entrepreneurs appear to be unfamiliar with new technologies. Those who seem to be well positioned, are most often unaware of this technology and if they know, it is not either locally available or not affordable or not situated to local conditions. Thus, foreign firms still remain in the forefront in accessing new technologies thus having a competitive edge over indigenous firms.

Consequently, MSMEs tend to have low productivity and they are weak in terms of competition which is the result of using inefficient technology, not maximizing machinery utility and not improving in technology due to the limitation of funding and most MSMEs are mainly users of technology, not adaptors of technology (OSMEP, 2007). The World Bank (2009) claims that investments in technology are required in order to build up existing capacity and to improve the quality and productivity of production which will generate higher value-added products that will improve the competitiveness of MSMEs.

In most of the African nations, Kenya inclusive, the challenge of connecting indigenous small enterprises with foreign investors and speeding up technological upgrading still persists (Muteti, 2005). There is digital divide between the rural and urban Kenya. With no power supply in most of the rural areas, it is next to impossible to have Internet connectivity and access to information and networks that are core in any enterprise. Thus technological change, though meant to bring about economic change even among the rural lot, does not appear to answer to the plight of the rural entrepreneurs. Similarly, poor infrastructures pose a major challenge to small enterprises in Kenya. In Kenya, the provision of better infrastructures has lagged behind over years. There are poor roads \& inadequate electricity supply.

\subsection{Entrepreneurial Policies}

Primarily, it is the prerogative of the government to create an enabling environment in which trade can thrive optimally for maximum return on investment (Madura, 2006). The policies that the government put in place can serve to promote or inhibit growth and sustainability of not only MSMEs but business entities in general. Ongile and McCormick (1996) indicate that early research treated MSMEs as peripheral survival mechanisms whose developmental impact was marginal though this view was to irrevocably change after the 1972 International Labour Organisation report that demonstrated the significant employment and wealth creation potential of the MSMEs. Additionally, Green et al. (2002) explains that previously many governments had policies slanting towards the promotion of large, capital intensive investors to the detriment of the MSMEs.

However, according to King (1996), the benign neglect has been replaced by the recognition that MSMEs could be the lynchpin for improving economic prospects in the developing world. Green et al. (2002) is of the view that compared with large enterprises, MSMEs are invariably more labourintensive and often more efficient and that they promote more equitable distribution of income than larger enterprises. The significance of MSMEs to the economy of most countries vis a vi the inherent challenges the sector faces prompted a number of institutions into action. The World Bank for instance, in an attempt to promote investment in MSMEs initiated support programs either directly to MSMEs or indirectly through governments, financial institutions and non-governmental organisations (Snodgrass \& Biggs, 1996; DFID, 2000, Grosh\&Somolekae, 1996; World Bank, 2004).

In Kenya, the government attempted to address the constraints facing MSMEs by developing policies and strategies contained in the Sessional Paper no. 2 of 1992 on Small Enterprise and Jua Kali Development and the Development Plan of 1989-1993. In these policy documents the problems facing MSMEs which were stringent collateral, low volume of credit to the sector and negative attitude of the banking sector were addressed. Subsequent major policy documents include the Sessional Paper Number 2 of 1996 on Industrial Transformation to the year 2020, and Sessional Paper Number 2 of 2005 on the Development of MSMEs for Employment and Wealth Creation (Republic of Kenya 1996, 2005; Caliceet al., 2012). 
These efforts have seen the participation of MSMEs in income generating activities increase as more people venture into the informal sector to garner additional income for their families. The exponential growth of the sector has turned the MSME segment into a strategic priority for the financial institutions, banks included (Caliceet al., 2012) and according to the researchers, MSMEs are now considered a profitable business prospect who provide an important opportunity for cross-selling. Additionally, it is alleged that bureaucratic hurdles particularly in developing countries like Kenya have encouraged corruption (Madura, 2006). Macroeconomic uncertainty like currency crashes, high inflation, and excessive budget deficits limit the ability to attract investments. Similarly, good infrastructure has a positive impact on investment flows (Asiedu, 2002), a fact emphasized in EPZA annual report of 2004 that the impediments faced by EPZ Enterprises stem from high cost of doing business in Kenya as a result of low labour productivity, depleted infrastructure, customs regulations and high cost of electricity and water. As such, researchers lament that Kenyan firms pay more unofficial fees, provide more for their own infrastructure and face more regulations than competitors in other countries (Ikiara\&Ndirangu, 2003). For instance, due to unreliable electricity supply, most firms are forced to install private power generators, which were unplanned expenditure (Wanyama, 2003).

Likewise, World Bank researchers argued that constrains that inhibits the growth of MSMEs are complex tax systems (World Bank, 2006). Also another shortcoming in South Eastern Europe is low level of trust in the court system to enforce claims, and the need to pay significant bribes for access to basic public services. For MSMEs to close the gap with their larger counterparts in the world of technology, further action by regional governments will be required with regard to improved infrastructure, costs and IT training and in information relating to the business opportunities that e.g. e-commerce can generate (Harvie\& Lee, 2005).

\section{OBJECTIVES OF THE STUDY}

The overall objective of this study was to determine the influence of non-financial factors on growth of MSMEs with specific focus on operators in the trade, service and agribusiness based MSMEs in Mombasa County, Kenya. Specifically, the study sought:

i. To determine the influence of operators' demographic factors on growth of the MSMEs.

ii. To establish the influence of enterprise location on growth of MSMEs.

iii. To determine the influence of technology integration on growth of the MSMEs.

iv. To determine the influence of entrepreneurial policies on growth of MSMEs.

\section{RESEARCH METHODOLOGY}

\subsection{Participants and Procedure}

Participants were 203 respondents out of the 764trade, service and agribased members registered with Micro \& Small Enterprises Authority, County Enterprises Development Mombasa County, under the ministry of Labour as at $30^{\text {th }}$ of April 2016. They were told that the study aimed at assessing the influence of non-financial factors on the growth of their MSMEs. They completed a questionnaire constructed by the researchers.

\subsection{Measures}

Respondents' demographics. Six variables were used to assess the contribution of respondents' demographics on the growth of MSMEs. Variables considered included gender, age, level of education, ownership status and training attendance status.

Enterprise location. Seven statements were used to assess the extent to which the respondents perceived aspects of enterprise location could be impacting the growth of MSMEs; all ratings were made on a 5-point scale (No extent $=1$, Little extent $=2$, Moderate extent $=3$, Great extent $=4$, Very great extent=5). A mean score of each item was computed.

Technology integration. Six statements were used to assess the extent to which technology integration were perceived to be impacting the growth of MSMEs; all ratings were made on a 5-point scale $(1=$ strongly disagree, $5=$ strongly agree). A mean score of each item was computed.

Entrepreneurial policies. Seven statements were used to determine the extent to which entrepreneurial policies could be impacting the growth of MSMEs; all ratings were made on a 5-point scale (No extent $=1$, Little extent $=2$, Moderate extent $=3$, Great extent $=4$, Very great extent=5). A mean score of each item was computed. 
Non - Financial Factors Influencing Entrepreneurial Growth of Agribusiness and Service Based Micro, Small and Medium Enterprises in Mombasa County, Kenya

Dependent Variable. Growth of MSMEs was measured based on the respondents' rating of their businesses relative to five metrics. A mean score of each item was computed.

\section{RESUlTS AND DISCUSSION}

\subsection{Entrepreneurial Growth of MSMEs}

The study principally sought to assess the extent to which non-financial factors predicted the entrepreneurial growth of agribased, trade and service based MSMEs. An inquiry was made from sampled respondents all of who were operators of such entities and findings were as is summarised in Table 1.

Table1. Extent of Growth of MSMEs

\begin{tabular}{|l|l|l|l|}
\hline Metric & Mean & SD & Rank \\
\hline Sales growth & 2.69 & .979 & 5 \\
Business assets growth & 3.11 & .807 & 2 \\
Business market share growth & 2.93 & 1.160 & 3 \\
Profit growth & 2.90 & 1.101 & 4 \\
Overall business output & 3.25 & .666 & 1 \\
Mean & $\mathbf{2 . 9 8}$ & $\mathbf{. 9 4 3}$ & \\
\hline
\end{tabular}

Results obtained show that the overall business output was the highest thus the high mean rating of 3.25 and standard deviation of 0.666 . It was closely followed by business assets growth $(\mathrm{M}=3.11$; $\mathrm{SD}=.807)$, then business market share growth $(\mathrm{M}=2.93 ; \mathrm{SD}=1.160)$ followed by profit growth $(\mathrm{M}=2.90 ; \mathrm{SD}=1.101)$ and lastly sales growth $(\mathrm{M}=2.69 ; \mathrm{SD}=.979)$ in decreasing order. The overall growth of the MSMEs was mean rated at 2.98 out of 5 and standard deviation of .943 . Being slightly more than the average, the findings imply that the growth of the MSMEs is relatively average and not as robust as would have been anticipated. This observation concurs with KNBS (2007) who indicated that MSMEs face unique problems, which affect their growth and profitability and, hence, diminishes their ability to contribute effectively to sustainable growth and development. This assertion is also supported by Amyx (2005) as well as Longenecker, et al. (2006).

\subsection{Respondents' Demographics and Growth of MSMEs}

Findings on respondents' demographic characteristics showed that $56.2 \%$ of the respondents were males, $90.2 \%$ were in the below 50 years age bracket and $78.8 \%$ had O-level and below educational qualification. Additionally, $64.0 \%$ were married and thus had responsibility, $94.1 \%$ were single owners of the entities and thus were solely responsible for their operation and success while only $17.7 \%$ had attended any training on business management. Chi - square analysis show that at .05 level of significance, respondents' level of education and seminar attendance have a significant influence on the growth of MSMEs, $\mathrm{X}^{2}=92.943 ; \mathrm{df}=3 ; \mathrm{P}<.001$ and $\mathrm{X}^{2}=15.449 ; \mathrm{df}=1 ; \mathrm{P}=.046$ respectively. Contingency coefficient measure of association indicated that $56.0 \%$ of the variation in influence could be attributed to the respondents' academic qualification and $26.2 \%$ of the variation of influence being attributed to seminar attendance. Regression analysis showed that level of education $(\beta=-2.175$; $\mathrm{P}<.001)$ and seminar attendance $(\beta=-3.109 ; \mathrm{P}<.001)$ are significant negative predictors of growth of MSMEs.

\subsection{Enterprise Location and Growth of MSMEs}

The study sought to establish the influence of enterprise location on the growth of MSMEs within the study area. Data obtained on the contribution of specific elements of enterprise location were as captured in Table 2.

Table2. Enterprise Location and Growth of MSMEs

\begin{tabular}{|l|l|l|l|}
\hline Statement & Mean & SD & Rank \\
\hline Accessibility of the business location to your & 3.04 & .933 & 7 \\
customers base & & & \\
Efficient accessibility for future clients & 3.72 & .947 & 3 \\
Costs of moving goods to business location & 3.39 & .874 & 4 \\
Costs of establishing business in the location & 3.82 & 1.197 & 2 \\
Labour costs on location & 3.23 & 1.033 & 6 \\
Transport costs on location & 3.32 & 1.024 & 5 \\
Proximity to suppliers & 3.89 & 1.155 & 1 \\
Mean & $\mathbf{3 . 4 9}$ & $\mathbf{1 . 0 2 3}$ & \\
\hline
\end{tabular}


The findings show that proximity to suppliers was conceived by the respondents to have the greatest contribution ( $\mathrm{M}=3.89 ; \mathrm{SD}=1.155)$ followed by cost of establishing business location $(\mathrm{M}=3.82$; $\mathrm{SD}=1.197)$, then efficient accessibility of future clients $(\mathrm{M}=3.72 ; \mathrm{SD}=.947)$ followed by cost of moving goods to business location $(\mathrm{M}=3.39 ; \mathrm{SD}=.874)$. Other elements ranked include transport cost on location $(\mathrm{M}=3.32 ; \mathrm{SD}=1.024)$, labour cost on location $(\mathrm{M}=3.23 ; \mathrm{SD}=1.033)$ and lastly accessibility of the business to customer base $(\mathrm{M}=3.04 ; \mathrm{SD}=.933)$. On the whole, the variable merited a mean rating of 3.49 out of 5 and a standard deviation of 1.023 implying that the factor has an influence on growth of the MSMEs. Regression analysis showed that the influence of enterprise location is positive and significant $(\beta=0.291 ; \mathrm{p}<.001)$. According to Nyaga (2013), when choosing locations, many different factors must be taken into account including labour costs, transport, and proximity to suppliers, workforce disruption, language factors, and exchange rates. Similarly, Herzonget al, (2009) maintains that the change that initiates a location search is the need for new production capacity to meet market demand. The change that that initiates a location search could be changes in perceived market opportunities, or changes in the entrepreneur's own situation.

\subsection{Technology Integration and Growth of MSMEs}

Similarly, the study sought to assess the respondents' perception of the existing relationship between technology integration and the entrepreneurial growth of MSMEs. The results were as is presented in Table 3.

Table3. Influence of Technology on Growth of MSMEs

\begin{tabular}{|c|c|c|c|}
\hline Statement & Mean & SD & Rank \\
\hline Low productivity is mainly due to use of inefficient technology & 3.55 & .790 & 5 \\
\hline Low investment in technology is due to the limitation of funding & 3.86 & .923 & 1 \\
\hline Investments in new technology improves productivity & 3.63 & 1.142 & 3 \\
\hline Use of technology aids in quick responses to customer demands & 3.81 & .937 & 2 \\
\hline Use of technology aids in accessing new markets & 3.56 & 917 & 4 \\
\hline Use of technology aids in building existing capacity to improve & 3.40 & 1.426 & 6 \\
\hline $\begin{array}{l}\text { quality and productivity } \\
\text { Mean }\end{array}$ & 3.64 & 1.023 & \\
\hline
\end{tabular}

The findings as captured in Table 3 show that a majority of the respondents insisted that their low investment in technology is due to the limitation of funding $(\mathrm{M}=3.86 ; \mathrm{SD}=0.923)$, that use of technology aids in quick responses to customer demands $(\mathrm{M}=3.81 ; \mathrm{SD}=0.937)$ and that investment in new technology improves productivity $(\mathrm{M}=3.63, \mathrm{SD}=1.142)$. Additionally, it was the contention of most of the respondents that use of technology aids in accessing new markets $(\mathrm{M}=3.56, \mathrm{SD}=.917)$, that their low productivity is mainly due to use of inefficient technology $(\mathrm{M}=3.55 ; \mathrm{SD}=.790)$ and that use of technology aids in building existing capacity to improve quality and productivity $(\mathrm{M}=3.40$, $\mathrm{SD}=1.426$ ). Overall, the respondents mean rated the influence of elements of technology integration at 3.64 out of 5 and a standard deviation of 1.023. The results imply that a significant proportion of the respondents believe that prompt technology integration promotes growth of the MSMEs. Regression analysis showed that its influence was similarly positive and significant $(\beta=0.367 ; p<.001)$. This agrees with the assertions of World Bank (2009) who claim that investments in technology are required in order to build up existing capacity and to improve the quality and productivity of production which will generate higher value-added products that will improve the competitiveness of MSMEs. As currently constituted, access and use of technology has posed a great challenge to small businesses (Calice, Chando\&Sekioua, 2012). Consequently, MSMEs tend to have low productivity and they are weak in terms of competition which is the result of using inefficient technology, not maximizing machinery utility and not improving in technology due to the limitation of funding and most MSMEs are mainly users of technology, not adaptors of technology (OSMEP, 2007).

\subsection{Entrepreneurial Policies and Growth of MSMEs}

Further, elements of entrepreneurial policies were probed to assess their influence on the growth of MSMEs. Their responses were as is summarized in Table 4. 
Non - Financial Factors Influencing Entrepreneurial Growth of Agribusiness and Service Based Micro, Small and Medium Enterprises in Mombasa County, Kenya

Table4. Influence of Entrepreneurial policies on Growth of MSMEs

\begin{tabular}{|l|l|l|l|}
\hline Factor & Mean & SD & Rank \\
\hline Complex tax system & 3.68 & 1.130 & 1 \\
VAT tax rate is affordable & 2.38 & 1.243 & 7 \\
Poor infrastructure including essential services such as & 3.49 & 1.119 & 3 \\
electricity, water etc. & & & \\
High rate of corruption & 3.24 & 1.480 & 5 \\
Poor basic business infrastructure & 2.68 & 1.198 & 6 \\
Low levels of information from governments on business & 3.37 & .921 & 4 \\
opportunities to entrepreneurs & & & \\
Weak legal infrastructure to enforce claims & 3.53 & 1.082 & 2 \\
Mean & $\mathbf{3 . 2 0}$ & $\mathbf{1 . 1 6 8}$ \\
\hline
\end{tabular}

Table4 contains information on respondents' perception about the influence of elements of entrepreneurial policies on the growth of MSMEs. Respondents scored highly for some of the elements. Specifically, a majority agreed that there exists a complex tax system thus the highest mean rating of 3.68 and standard deviation of 1.130. Similarly, a majority of the respondents were categorical that there exist a weak legal infrastructure to enforce claims $(\mathrm{M}=3.53 ; \mathrm{SD}=1.082)$, that there is poor infrastructure including essential services such as electricity, water etc $(M=3.49$, $\mathrm{SD}=1.119$ ), that there is low levels of information from governments on business opportunities to entrepreneurs $(\mathrm{M}=3.37 ; \mathrm{SD}=.921)$, there is high rate of corruption $(\mathrm{M}=3.24 ; \mathrm{SD}=1.480)$, there is poor basic business infrastructure $(\mathrm{M}=2.68 ; \mathrm{SD}=1.198)$ and the VAT tax rate is affordable $(\mathrm{M}=2.38$; $\mathrm{SD}=1.243$ ). Thus the element attained a mean ranking of 3.20 and standard deviation of 1.168 indicating that a majority of the respondents perceive entrepreneurial policies to be of influence on the growth of MSMEs. Regression analysis showed that its influence is negative and significant $(\beta=-$ 0.234; $\mathrm{P}<0.001$ ). The findings are in tandem with those of previous researchers. EPZA annual for instance in their report of 2004 point that the major impediments faced by EPZ Enterprises stem from high cost of doing business in Kenya as a result of low labour productivity, depleted infrastructure, customs regulations and high cost of electricity and water. As such, researchers lament that Kenyan firms pay more unofficial fees, provide more for their own infrastructure and face more regulations than competitors in other countries (Ikiara\&Ndirangu, 2003). For instance, due to unreliable electricity supply, most firms are forced to install private power generators, which were unplanned expenditure (Wanyama, 2003). Likewise, World Bank researchers argued that constrains that inhibits the growth of MSMEs are complex tax systems (World Bank, 2006), low level of trust in the court system to enforce claims, and the need to pay significant bribes for access to basic public services.

\section{IMPLICATIONS, LIMITATIONS AND CONCLUSIONS}

\subsection{Implications for MSMEs}

The findings illustrated that the growth of MSMEs is influenced by a number of non-financial factors including operators' demographic factors, enterprise location, technology integration and entrepreneurial policies. Since the study noted thatoperators' level of education, seminar attendance and entrepreneurial policiesare the main inhibitors of the growth of the entities, effort need to be put in place to check their negative contributions thus spur the growth of the MSMEs. Specifically, operators should be encouraged to upgrade their level of education by enrolling in continuing education programs. At the same time programs such as seminars on business management should be regularly organized and operators' of MSMEs be encouraged to attend. Lastly, relevant government department should formulate and implement policies that foster the growth of the MSMEs. Priority should be given to enhancement of infrastructure, formulation of simple and sector friendly tax regime as well as strengthening of legal infrastructure including that of claims.

\subsection{Limitations and Directions for Further Research}

The main limitation of this study rests on its quantitative methodology which mainly depended on self-report measures. It is encouraged that future studies could build on these by applying mixed study methods as well as longitudinal studies that can track changes in thinking processes of operators of MSMEs. 


\section{CONCLUSION}

In general, the study provides a sneak preview of the contributions of non-financial factors on the growth of MSMEs, the Kenyan context. It suggest that proprietors' low level of education, their nonattendance of seminars and the sector unfriendly policies are the main inhibitors of MSMEs' growth. The results show that stakeholders including the government through its relevant departments need to seriously consider putting in place mechanisms of addressing these gaps in order to foster the growth of MSMEs which is an important sector of the country's economy.

\section{REFERENCES}

Amyx, C. (2005). Small Business Challenges. The Perception Problem: Size Doesn't Matter. Washington Business Journal, 5(2), 89-99

Aris, N. M. (2007). SMEs: Building Blocks for Economic Growth. Department of Statistics Malaysia

Asiedu, E. (2002). On the determinants of foreign direct investment to developing countries: is Africa different?.World development, 30(1), 107-119.

Calice, P.; Chando, V. M. \&Sekioua, S. (2012). Bank Financing to Small and Medium Enterprises in East Africa: Findings of A Survey in Kenya, Tanzania, Uganda and Zambia, Working Paper Series $\mathrm{N}^{\circ} 146$, African Development Bank, Tunis, Tunisia

DFID. (2000). Eliminating World Poverty: Making Globalisation Work for the Poor. The Department for International Development: London.

Green C.J, Kimuyu P, Manos R, \&Murinde V. (2002). How do small firms in developing countries raise capital? Evidence from a large-scale survey of Kenyan MSEs. Finance and Development Working Paper No. 54. Univeristy of Manchester: Manchester.

Grosh B \&Somolekae G. (1996). Mighty oaks from little acorns: can microenterprise serve as the seedbed of industrialization? World Development 24: 1879-1890.

International Labour Organization 1989.A strategy for small enterprise development towards the year 2000. Nairobi, Kenya.

Longenecker, J.G., Moore, C.W. \& Petty, J.W. (2003).Small Business Management: An Entrepreneurial Emphasis, 12th edition. Ohio: South-Western.

Macpherson, A. \& Holt, R. (2007) Knowledge, learning and small firm growth: A systematic review of the evidence, Research Policy

Ongile, G. \& McCormick, D., (1996). "Barriers to small enterprise growth: Evidence from Nairobi's small garment industry", in D. McCormick and P.O. Perderson (eds), Small Enterprise: Flexibilty and Networking in an African Context, Longhorn, Nairobi.

Republic of Kenya (1996). 'Sessional Paper Number 2 of 1996 on Industrial Transformation to the Year 2020’. Nairobi: Government Printer.

Republic of Kenya (2005). 'Sessional Paper Number 2 of 2005 on the Development of Micro and Small Scale Enterprises for Wealth and Employment Creation for Poverty Reduction'. Nairobi: Government Printer.

Saleh, A. S. \&Ndibisi, N. O. (2006).An Evaluation of SME Development in Malaysia.International Review of Business Research Papers 2(1), 1-14

Wambugu, W. J. \&Ngugi, K. (2013). Factors Contributing to Loan Delinquency in agribased Small and Medium Enterprises in Kenya: A Case of The Agricultural Finance Corporation, International Journal of Social Sciences and Entrepreneurship. 1(2), 470-483.

World Bank.(2004). World Bank Group Support for Small Businesses. World Bank: Washington, DC 
Non - Financial Factors Influencing Entrepreneurial Growth of Agribusiness and Service Based Micro, Small and Medium Enterprises in Mombasa County, Kenya

\section{AUTHORS' BIOGRAPHY}

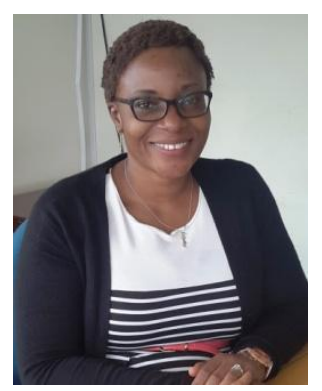

Ms. Josephine Jackline Sanya, is a prospective MSC in Entrepreneurship candidate from Jomo Kenyatta University of Agriculture \& Technology. She is an experienced banker and financial expert, Sanya holds a Bachelors of Commerce Degree (Finance) from the University of Nairobi.

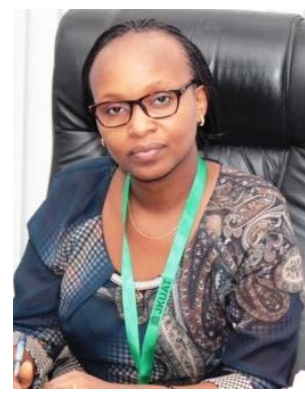

Dr Fridah Theuri (PHD), is the Director - Mombasa Campus of Jomo Kenyatta University of Agriculture and Technology. She is a Senior Lecturer in the School of Human Resource Development. 